\title{
Evaluation of external and internal irradiation on uranium mining enterprise staff by tooth enamel EPR spectroscopy
}

\author{
Kassym Zhumadilov ${ }^{1, *}$, Alexander Ivannikov ${ }^{2}$, Artem $\mathrm{Khailov}^{2}$, Sergei Orlenko ${ }^{2}$, Valeriy \\ Skvortsov $^{2}$, Valeriy Stepanenko ${ }^{2}$, Kairat Kuterbekov ${ }^{1}$, Shin Toyoda ${ }^{3}$, Polat Kazymbet ${ }^{4}$, and \\ Masaharu Hoshi $^{5}$ \\ ${ }^{1}$ L.N. Gumilyov Eurasian National University, Munaitpasova 13, Astana 010008, Kazakhstan \\ ${ }^{2}$ A.F. Tsyb Medical Radiological Research Center, 4, Korolev str., Obninsk, 249036, Russia \\ ${ }^{3}$ Department of Applied Physics Faculty of Science Okayama University of Science, 700-0005, Japan \\ ${ }^{4}$ Institute of Radiobiological Research, Astana 010008, Kazakhstan \\ ${ }^{5}$ Hiroshima University, 734-8553, Japan
}

\begin{abstract}
In order to estimate radiation effects on uranium enterprise staff and population teeth samples were collected for EPR tooth enamel dosimetry from population of Stepnogorsk city and staff of uranium mining enterprise in Shantobe settlment (Akmola region, North of Kazakhstan). By measurements of tooth enamel EPR spectra, the total absorbed dose in the enamel samples and added doses after subtraction of the contribution of natural background radiation are determined. For the population of Stepnogorsk city average added dose value of $4+/-11 \mathrm{mGy}$ with variation of $51 \mathrm{mGy}$ was obtained. For the staff of uranium mining enterprise in Shantobe settlment average value of added dose $95+/-20 \mathrm{mGy}$, with $85 \mathrm{mGy}$ variation was obtained. Higher doses and the average value and a large variation for the staff, probably is due to the contribution of occupational exposure.
\end{abstract}

\section{Introduction}

At the mining of uranium ore in the world a large number of people is employed. Most of the uranium ore is mined in mines and open pits. At that personnel of mines and quarries are at an increased risk of irradiation from the isotopes of uranium and its decay products. Only for some ore fields, the mining with using of the safer method of underground leaching is available. Radiation threat is also represented by piles of waste of uranium deposits.

Kazakhstan is the largest producer of uranium. It is on the first place in world uranium production (39.3\% of world production in 2016) and the second place on its reserves [1]. A significant portion of Kazakhstan's uranium reserves (about 18\%) is concentrated in the Northern Kazakhstan uranium ore province $[2,3]$.The bulk of the production of uranium ore from the mid 50-ies of the last century, there were carried out here in the mines and open pits.

In the places of uranium mining radiation-ecological monitoring, as well the

\footnotetext{
* Corresponding author: zhumadilovk@gmail.com
} 
individual control of doses is typically carried out. However, this is not enough to properly assess the radiation doses. It is therefore important to estimate the doses by independent methods. One of such methods is the EPR (electron paramagnetic resonance) dosimetry using tooth enamel [4-7]. This method can estimate individual accumulated absorbed dose through more than 50 years after exposure to radiation. Dose determination is based on the measured by EPR spectroscopy amount of stable radicals formed in the enamel after exposure to ionizing radiation. This method uses enamel samples prepared from teeth extracted according to medical indications. The error of determination of absorbed dose by this method is about 30-50 mGy [8-12].

Particularly important is the assessment of the radiation effects of uranium mining enterprises on their personnel and on the population of adjacent territories at the North of Kazakhstan. For this aim, a survey was conducted by EPR dosimetry for the personnel of uranium mine placed near Shantobe settlement and for population of this settlement placed in this region. Also such survey was performed for population of Stepnogorsk city in this region, where the uranium ore processing enterprise is placed and waste dumps of this enterprise are located in the vicinity from this city [2].

\section{Materials and Methods}

\subsection{Sample collection}

Teeth samples collection according to medical indication were carried from population of Stepnogorsk city and staff of uranium mining enterprise (mine) located near Shantobe urban-type settlement (Akmola region of Kazakhstan) located $180 \mathrm{~km}$ to the North from Astana city, the capital of Kazakhstan. Totally, more than a hundred teeth samples were collected with purpose to separate tooth enamel from dentin for EPR dosimetry.

The two groups of enamel samples were prepared from teeth collected as extracted according to medical indications in local dental clinics. A group of samples indicated with number codes $97 \mathrm{St}-119 \mathrm{St}$ (23 teeth) was collected from population of Stepnogorsk city. Another group indicated with codes 67 Sh-96 Sh (30 teeth) was collected in Shantobe settlement, part of population of which is engaged as a stuff of uranium mine. Part of these samples $78 \mathrm{Sh}-96 \mathrm{Sh}$ (19 teeth) was collected from the uranium mine personnel, another part, $67 \mathrm{Sh}-77 \mathrm{Sh}$ (11 teeth) - from population of another occupation not directly connected with work in uranium mine. For each sample information was supplied about teeth type (teeth position) and individual information about teeth donors (name, birth date, address, occupation, x-ray diagnostic procedures).

Stepnogorsk city is the center, where the processing of uranium ore from Northern Kazakhstan ore uranium province is performed. This city is located $200 \mathrm{~km}$ to north of Astana, capital of Kazakhstan. The ore is delivered from mines of Shantobe, which is located $400 \mathrm{~km}$ to the west from Stepnogorsk. Also, it is processing uranium ore concentrates produced in other ore fields of Kazakhstan. Population of Stepnogorsk is about 69000 (in 2016). Population of Shantobe urban-type settlement is about 3700 (in 2016). Part of them (about 700) is engaged as personal of uranium ore mine placed in $7 \mathrm{~km}$ near this settlement $[13,14]$.

\subsection{Sample preparation}

Enamel samples were prepared separately from outer (buccal) and inner (lingual) sides of teeth $[10,11]$. The assignment of the samples to the inner and outer sides of the teeth carried by the appearance of samples based on the analysis of the shape of the tooth in consultation with the dentists. Enamel was separated from dentin using dental drill. In order to avoid mechanical induced signal, in final stage of enamel separation hard allow burs 
were used at lowed rotation speed. After separation, enamel was cut to chips $0.5-1.0 \mathrm{~mm}$ in size with hard alloy nippers. Sample mass for measurement was in the range of 40-120 $\mathrm{mg}$. The lower mass limit is defined by availability of enamel and by EPR sensitivity limitation. For molars and premolars (teeth with positions 4-8), enamel from both sides of tooth was used for analysis. For incisors and canines (positions 1-3) only enamel from inner side was used, since in enamel from outer side the signal is induced because of the effect of the solar light UV component [15-19].

\subsection{EPR spectra measurement and dose determination}

EPR spectra measurements were performed with the use of the EPR spectrometer ESP-300 E (Bruker) in X-band $(9.8 \mathrm{GHz})$ equipped by the standard cavity with the following registration parameters: center field $390 \mathrm{mT}$, sweep width $10 \mathrm{mT}$, modulation $0.3 \mathrm{mT}$, microwave power $10 \mathrm{~mW}$, total time of spectra measurement with accumulations 40 min. The third line of the $\mathrm{MnO}$ marker sample build in the cavity was together with enamel spectra. Spectra processing was performed with the use the basic software of the spectrometer's build-in computer under manual control similar as it is described in our previous publications [20-23]. The radiation-induced signal was obtained after subtraction of the simulated native signal fitted under the operator control. For such simulation, a spectrum of not irradiated enamel was used.

Dose in enamel was determined from the amplitude of the radiation-induced signal measured as its maximum and normalized by sample mass, $\mathrm{MnO}$ marker signal amplitude and by calibration coefficient. Calibration of the enamel dose response was performed using the set of samples prepared from pulled enamel irradiated by a cobalt-60 gamma source in different doses controlled by a tissue-equivalent dosimeter. Therefore, dose in enamel was obtained in terms of tissue equivalent dose according to cobalt-60 gamma calibration.

Additional dose in enamel caused by technogenic radiation was determined by subtraction from the total dose of the contribution caused by natural background radiation since enamel formation with dose rate $0.8 \mathrm{mGy}$ per year [24, 25].

\section{Results and discussion}

To estimate the dose determination error, the correlation between the doses determined for the enamel from the inside and outside of the teeth has been analyzed (Figure 1). For some samples the increased difference between doses for internal and external enamel was observed (samples \#70, 91, 96 with tooth positions 7, 6 and 6 respectively). Such data were excluded from further analysis as outliers. Perhaps this increased difference is due to increased signal in outer enamel because of possible irradiation at X-ray diagnostics of teeth. Since the assignment of the samples to the inner and outer sides of the teeth was carried by the appearance of samples, such assignment may be mistaken, especially for molar teeth at high damages by caries.

Based on the analysis of correlation between the doses determined for the enamel from the inner and outer sides of the teeth, it is possible to get an idea of experimental error in determining the dose. The root mean-square (RMS) of the difference between doses gives the resulting error of both doses for which the difference was estimated. For each value contributing to this difference the error will be $2^{1 / 2}$ times less. From the estimated value of RMS within 60-76 mGy it follows that error in determining of dose for each enamel sample is about $40-50 \mathrm{mGy}$. 

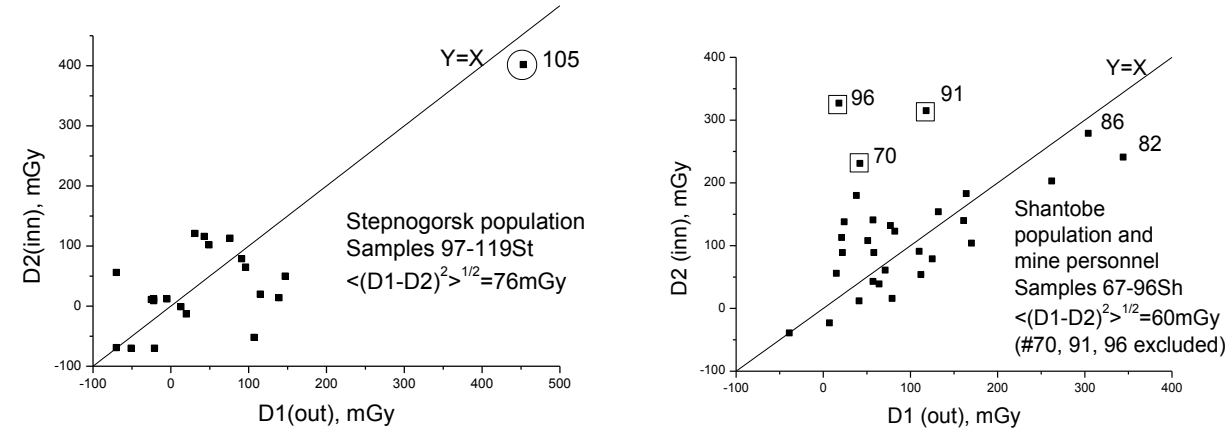

a

b

Fig. 1. Relation between total doses in enamel measured for outer (D1) and inner (D2 ) sides of teeth: $\mathrm{a}-$ for Stepnogorsk population; $\mathrm{b}$ - for Shantobe population and mine personnel. Line with unit slope $(\mathrm{Y}=\mathrm{X})$ is shown for comparison. The squares mark results, which were rejected from further processing as outliers because of anomalous high difference between inner and outer doses.

Dependencies of the added dose on the age of the enamel are shown in Figure 2. Histograms of the distribution of added doses are shown in Figure 3. The values of average doses, uncertainty of the average and their variation (standard deviation from the mean) are presented in the fields of figures.
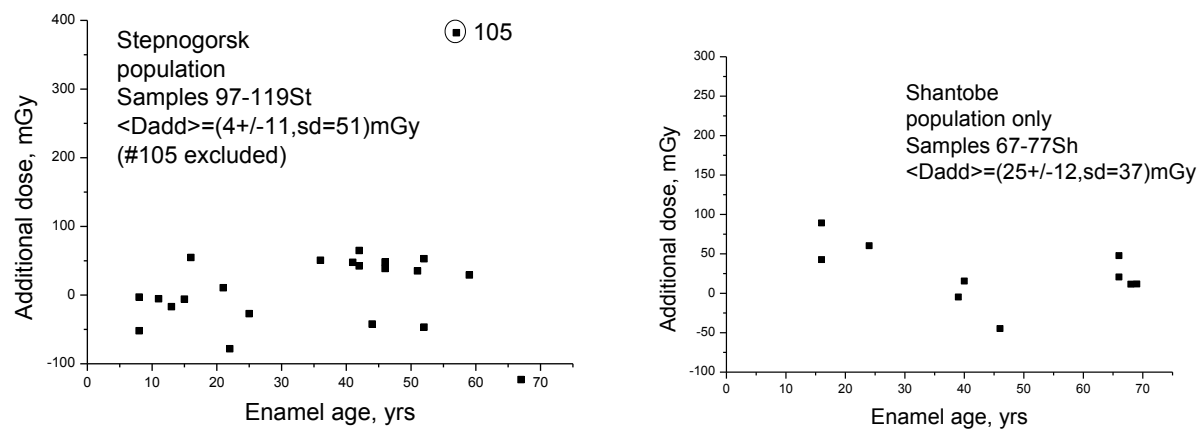

a

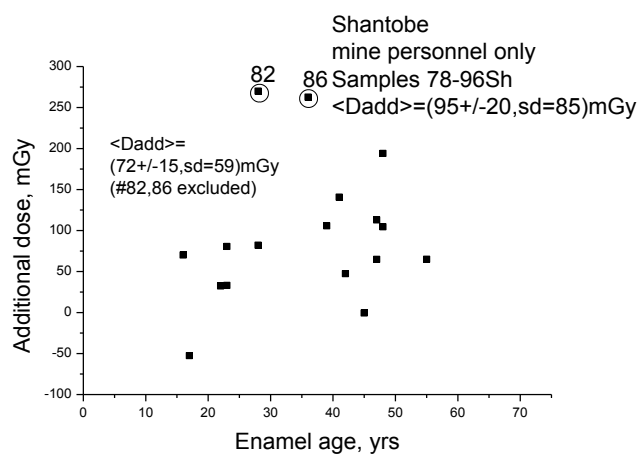

Fig. 2. Dependencies of additional doses on the enamel age: $a-$ for Stepnogorsk population; $b$ - for Shantobe population; $\mathrm{c}$ - for Shantobe mine personnel. The circles mark increased doses. 

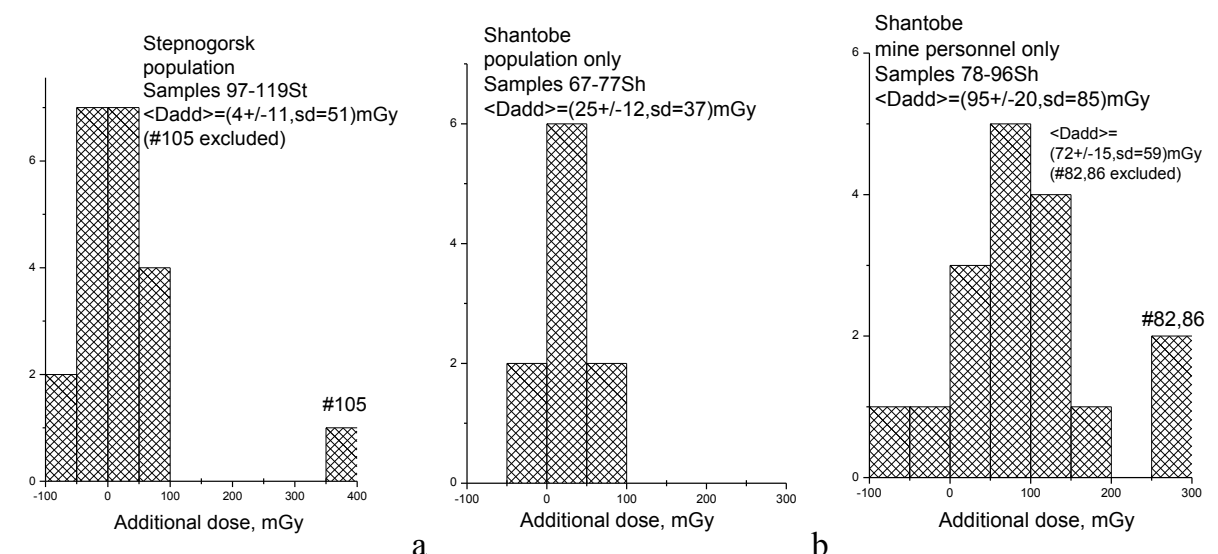

Fig. 3. Distribution histograms of additional doses: $a$ - for Stepnogorsk population; $b$ - for Shantobe population; $\mathrm{c}$ - for Shantobe mine personnel.

On the basis of measurements a statistical analysis of the added dose values was carried out separately for groups of population and for personnel. For the population of Stepnogorsk (97-119 St samples) the average value of the added dose is obtained $4+/-11 \mathrm{mGy}$, with $51 \mathrm{mGy}$ variation. These values were obtained after excluding from the calculation of high-dose value for the sample \#115. Probably, the donor of this sample was in places with high radiation. The magnitude of the variation of doses roughly equivalent to the dose estimation error, and this error determines the width of the distribution of doses. The average dose is close to zero. This indicates the absence of man-made radiation for this group of the population.

For the population of Shantobe settlement average added dose is $25+/-12 \mathrm{mGy}$. This value is significantly higher than for the population Stepnogorsk. This is probably due to the proximity of uranium mines. Variation value of $37 \mathrm{mGy}$ is close to the error of the method.

For the personnel of the Shantobe mine average added dose is $95+/-20 \mathrm{mGy}$, which is significantly higher than for the rest of the population Shantobe and for Stepnogorsk population. The variation of the dose values of $85 \mathrm{mGy}$ significantly exceeds the error of the method, and probably is due to the different radiation exposure to staff according to their working conditions. Noteworthy higher dose values for two people, samples \#82 and \#86, which is probably caused by the special conditions of their work.

According to published data for the results of a conventional personal dosimetry, when working in uranium mines, the level of external exposure of an average of about $10 \mathrm{mGy}$ per year [26]. This value is consistent with the average value obtained by EPR dosimetry, if to assume the work in the mine for about 10 years.

\section{Conclusion}

On the basis of measurements a statistical analysis of the values added doses separately for groups and staff were carried out. For the population of the Stepnogorsk city dose value from 4 +/- $11 \mathrm{mGy}$ to $51 \mathrm{mGy}$. For staff of uranium mining enterprise in the Shantobe village average value of dose $95+/-20 \mathrm{mGy}, 85 \mathrm{mGy}$ variation. Higher doses and the average value of a large variation of the staff, probably due to the contribution of occupational exposure. Possibly, part of the contribution of radiation due to internal alpha source in the soft tissues. In the next phase of the study it is planned to allocate this contribution by examining EPR enamel samples after etching of the surface layer. 


\section{Acknowledgements}

This work was supported partly by the Ministry of Education and Science of Kazakhstan (5284/GF4 agreement No. 47) and by Russian Foundation of Basic Research (15-58-45050 IND_a and 16-04-01276), which is greatly appreciated.

\section{References}

1. Uranium 2016: Resources, Production and Demand. Joint report by the OECD Nuclear Energy Agency and the International Atomic Energy Agency. http://www.oecdnea.org/ndd/pubs/2016/7301-uranium-2016.pdf

2. K. Zhumadilov, A. Ivannikov, V. Stepanenko, Sh. Abralina, L. Sadvokasova, A. Akilbekov, A. Morzabayev, T. Rakhypbekov, M. Hoshi, Radiat. Environ. Biophys. 54, 4 (2015)

3. Mining of uranium (in Russian)

http://www.kazatomprom.kz/ru/content/kompaniya/deyatelnost/dobycha-prirodnogo-urana

4. IAEA-TECDOC-1331, Vienna (2002)

http://www-pub.iaea.org/MTCD/publications/PDF/te_1331_web.pdf

5. E. Tielewuhan, A. Ivannikov, K. Zhumadilov, M. Nalapko, D. Tikunov, V. Skvortsov, V. Stepanenko, Sh. Toyoda, K. Tanaka, S. Endo, M. Hoshi, Radiat. Meas. 41, 7 (2006)

6. K. Tanaka, S. Endo, A. Ivannikov, S. Toyoda, E. Tieliewuhan, K. Zhumadilov, C. Miyazawa, S. Suga, K. Kitagawa, M. Hoshi, J. Radiat. Res. 46, 4 (2006)

7. K. Zhumadilov, V. Stepanenko, A. Ivannikov, Z. Zhumadilov, S. Toyoda, K. Tanaka, S. Endo, M. Hoshi, Radiat. Environ. Biophys. 47, 4 (2008)

8. V.G. Skvortsov, A.I. Ivannikov, V.F. Stepanenko, A.F. Tsyb, L.H. Khamidova, A.E. Kondrashov, D.D. Tikunov, Appl. Radiat. Isot. 52, 7 (2000)

9. P. Fattibene, A. Wieser, E. Adolfsson, L.A. Benevides, M. Brai, F. Callens, V. Chumak, B. Ciesielski, S. Della Monaca, K. Emerich, H. Gustafsson, Y. Hirai, M. Hoshi, A. Israelsson, A. Ivannikov, D. Ivanov, J. Kaminska, Wu Ke, E. Lund, M. Marrale, L. Martens, C. Miyazawa, N. Nakamura, W. Panzer, S. Pivovarov, R.A. Reyes, M. Rodzi, A.A. Romanyukha, A. Rukhin, S. Sholom, V. Skvortsov, V. Stepanenko, M.A. Tarpan, H. Thierens, S. Toyoda, F. Trompier, E. Verdi, K. Zhumadilov, Radiat. Meas. 46, 6 (2011)

10. K.S. Zhumadilov, A.I. Ivannikov, V.G. Skvortsov, Zh. Zhumadilov, S. Endo, K. Tanaka, M. Hoshi, J. Radiat. Res. 46, 7 (2005)

11. K. Zhumadilov, A. Ivannikov, K. Apsalikov, Zh. Zhumadilov, V. Stepanenko, V. Skvortsov, G. Berekenova, S. Toyoda, S. Endo, K. Tanaka, C. Miyazawa, M. Hoshi, Radiat. Meas. 42, 4 (2007)

12. A.I. Ivannikov, D. Sanin, M. Nalapko, V.G. Skvortsov, V.F. Stepanenko, A.F. Tsyb, F. Trompier, K. Zhumadilov, M. Hoshi, Health Phys. 98, 6 (2010)

13. Stepnogorsk (in Russian) - https://ru.wikipedia.org/wiki/Степногорск

14. Shantobe (in Russian) - https://ru.wikipedia.org/wiki/Шантобе

15. A.I. Ivannikov, V.G. Skvortsov, V.F. Stepanenko, D.D. Tikunov, A.A. Romanyukha, A. Wieser, Radiat. Prot. Dosim. 71, 5 (1997) 
16. A. Ivannikov, K. Zhumadilov, E. Tieliewuhan, L. Jiao, K.N. Apsalikov, G. Berekenova, Zh. Zhumadilov, Sh. Toyoda, C. Miyazawa, V. Skvortsov, V. Stepanenko, S. Endo, K. Tanaka, M. Hoshi, J. Radiat. Res. 47, 7 (2006)

17. A.I. Ivannikov, V.G. Skvortsov, V.F. Stepanenko, K.Sh. Zhumadilov, Radiat. Prot. Dosim. 159, 4 (2014)

18. K. Zhumadilov, A. Ivannikov, K.N. Apsalikov, Zh. Zhumadilov, Sh. Toyoda, E. Tieliewuhan, S. Endo, K. Tanaka, C. Miyazawa, T. Okamoto, M. Hoshi, J. Radiat. Res. 47, 6 (2006)

19. K. Zhumadilov, A. Ivannikov, Z. Zhumadilov, V. Stepanenko, K. Apsalikov, M. Rodzi, A. Zhumadilova, S. Toyoda, S. Endo, K. Tanaka, T. Okamoto, M. Hoshi, Radiat. Environ. Biophys. 48, 6 (2009)

20. K. Zhumadilov, A. Ivannikov, V. Stepanenko, S. Toyoda, Z. Zhumadilov, M. Hoshi, J. Radiat. Res. 54, 4 (2013)

21. A. Wieser, E. Vasilenko, P. Fattibene, S. Bayankin, N. El-Faramawy, D. Ivanov, P. Jacob, V. Knyazev, S. Onori, M.C. Pressello, A. Romanyukha, M. Smetanin, A. Ulanovsky, Radiat. Environ. Biophys. 44, 9 (2006)

22. M. Hoshi, S. Toyoda, A. Ivannikov, K. Zhumadilov, A. Fukumura, K. Apsalikov, Z.S. Zhumadilov, S. Bayankin, V. Chumak, B. Ciesielski, V. De Coste, S. Endo, P. Fattibene, D. Ivanov, C.A. Mitchell, S. Onori, M. Penkowski, S.P. Pivovarov, A. Romanyukha, A.B. Rukhin, K. Schultka, T.A. Seredavina, S. Sholom, V. Skvortsov, V. Stepanenko, K. Tanaka, F. Trompier, A. Wieser, G. Wolakiewicz, Radiat. Meas. 42, 9 (2007)

23. A. Ivannikov, S. Toyoda, M. Hoshi, K. Zhumadilov, A. Fukumura, K. Apsalikov, Z.S. Zhumadilov, S. Bayankin, V. Chumak, B. Ciesielski, V. De Coste, S. Endo, P. Fattibene, D. Ivanov, C.A. Mitchell, M Nalapko, S. Onori, M. Penkowski, S.P. Pivovarov, A. Romanyukha, A.B. Rukhin, D. Sanin, K. Schultka, T. Seredavina, S. Sholom, V. Skvortsov, V. Stepanenko, K. Tanaka, F. Trompier, A. Wieser, G. Wolakiewicz, Radiat. Meas. 42, 5 (2007)

24. V.F. Stepanenko, M. Hoshi, Yu.V. Dubasov, A. Sakaguchi, M. Yamamoto, M. Orlov, I.K. Bailiff, A.I. Ivannikov, V.G. Skvortsov, I.G. Kryukova, K.S. Zhumadilov, K.N. Apsalikov, B.I. Gusev, J. Radiat. Res. 47, 9 (2006)

25. V.F. Stepanenko, M. Hoshi, A.I. Ivannikov, I.K. Bailiff, K. Zhumadilov, V.G. Skvortsov, R. Argembaeva, A.F. Tsyb, Radiat. Meas. 42, 7 (2007)

26. Exposure at uranium mining (in Russian) http://chornobyl.ru/radiacia/46-urandobucha-obluchenie.html 